\title{
MODELING COMMUNICATION SYSTEMS TO STUDY THE EFFECT OF INTERFERENCE IN THE TRANSMISSION MEDIUM
}

Kvasnikov V. P. - Professor, Dr. Sc., Head of Computerized Electrical Systems and Technologies Department of the National Aviation University, Kyiv, Ukraine.

Yehorov S. V. - PhD, Associate Professor of Computerized Electrical Systems and Technologies Department of the National Aviation University, Kyiv, Ukraine.

Shkvarnytska T. Yu. - Associate Professor, PhD, Associate Professor of Computerized Electrical Systems and Technologies Department of the National Aviation University, Kyiv, Ukraine.

Ornatskyi D. P. - Dr. Sc., Professor of Computerized Electrical Systems and Technologies Department of the National Aviation University, Kyiv, Ukraine.

Kataieva M. A. - PhD, Associate Professor of Computerized Electrical Systems and Technologies Department of the National Aviation University, Kyiv, Ukraine.

\begin{abstract}
Context. The problem of creating a model of transmission and transformation of information has been resolved, the processes of information transformation in transmitters and receivers have been considered, the process of influence of the destabilizing factors in the communication channel has been investigated.

Objective. The study aims to create a mathematical model of the communication channel, taking into account the destabilizing factors that affect the transmission channel and control the correctness of the communication channel model.

Method. A mathematical model, which evaluates the stability of the signal in the communication channel at the stage of designing telecommunication systems for various purposes, taking into account the effects of destabilizing factors in the environment of information signal transmission, is proposed. It is also a proposed method of determining the parameters of information signals in the communication channel and the increase in the bandwidth during exposure of external destabilizing factors on the signal transmission medium in the communication channel.

Results. A mathematical model of the communication channel was obtained, which takes into account external destabilizing factors that can affect the communication channel and equipment. The developed model contains a method of verification, which allows determining its correctness.

Conclusions. The method of information transfer has been improved by adding a verification method. The value of the bit error obtained during the simulation of the communication channel coincides with the value of the bit error during the verification process, which indicates the correctness of the considered mathematical model of the communication channel. The modeling of the communication channel confirmed the adequacy of the proposed method of modeling the communication system, so this method can be recommended for use in the design and research of telecommunications systems.
\end{abstract}

KEYWORDS: communication channel, modulation, communication quality, signal recovery, demodulation, filtering.

\author{
ABBREVIATIONS \\ QPSK is a Quadrature Phase Shift Keying; \\ MIMO is a Multiple Input Multiple Output; \\ OFDM is an Orthogonal Frequency-Division Multi- \\ plexing; \\ LC-RoF is a linear-cell-based radio-over-fiber; \\ LTE is a Long-Term Evolution; \\ VLC is a Visible Light Communication; \\ PLC is a Power Line Communication; \\ BER is a Bit Error Rate; \\ AWGN is an Additive White Gaussian Noise; \\ $\mathrm{BPM}$ is a binary phase manipulation.
}

\section{NOMENCLATURE}

$M$ is the number of characters in the alphabet;

$R$ is a source performance;

$T_{M}$ is a time interval;

$k$ is the number of binary units of information in one character;

$T$ is a signal duration;

$n$ is the number of binary signals;

$E$ is the energy that falls on the $M$-th symbol;

$E_{2}$ is the energy per binary unit (bit) of the source;

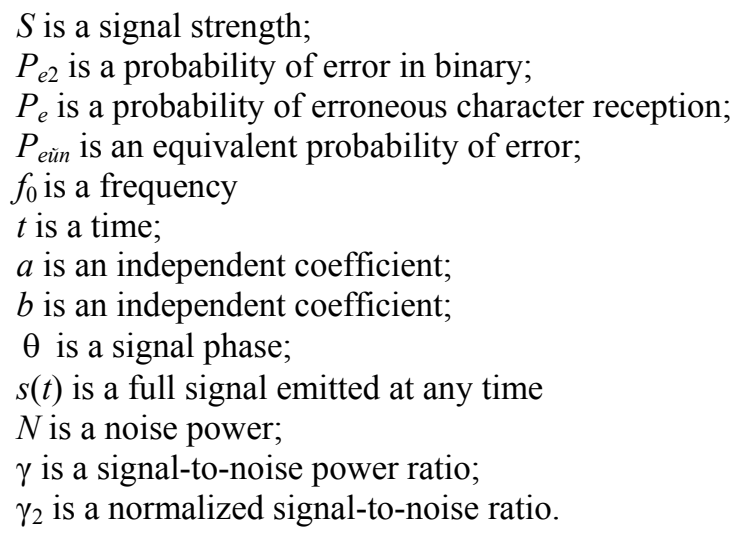

\section{INTRODUCTION}

The design of telecommunication systems requires a careful study of the principles of information, the properties of communication channels, as well as existing systems for transmitting and receiving signals. The rapid pace of development of science and technology has caused the growth of industry and telecommunications services. 
Selecting and designing a communication channel without proper study of the systems that affect the transmission medium can lead to complete or partial data loss. The first step in preventing the loss of information in communication channels during the development of data transmission systems is to model the processes of conversion and transmission of information taking into account external influences.

The task of developing a mathematical model of transmission and transformation of information, including transmitter and receiver, is relevant and determines the direction of research.

The object of the study is the process of formation, transmission, and recovery of radio signals.

The purpose of the study is to create a mathematical model of a communication system that takes into account the destabilizing factors that act on the transmission channel and controls the correctness of the communication channel model.

\section{PROBLEM STATEMENT}

In almost every electrical measurement or generated signal, there are unwanted components that mix with the useful signal. Noise is an unwanted component of a signal from any source. If the required signals are very weak, they can be completely lost against a background of higher noise levels.

In general, sources of unwanted noise power can be classified as internal or external noise. Internal noise occurs when unwanted random signal power appears at the output of an electronic device, despite its absence at the output of the device that generates the useful signal. Internal noise is generated inside the device. On the other hand, the power of external noise is regarded as combined unwanted sources of electrical signal that are received by the device from any external source.

All the above facts are the cause of errors in detecting a useful signal. To avoid such errors, it is necessary at the stage of designing communication systems to analyze the resistance of the system to external and internal interference using mathematical modeling.

To achieve this goal, a mathematical model was proposed, the essence of which is as follows. It is suggested to choose a mathematical model of the communication system as input data. This model should receive information modulating signals that can be obtained using a random number generator. In the mathematical model of the transmitter, the carrier frequency signals are modulated. These signals are summed and transmitted to the communication channel, where they are exposed to external influences generated by the simulation system. In the receiver, the additive mixture of signals is restored by a demodulator, which is described by the difference equation and uses bandpass filters. The degree of similarity of the recovered signal to the modulating signal in the communication channel model is estimated by the probability of bit error by comparing the signal at the input of the communication system model and the output of the model. The Bit Error Rate Analysis Tool of the MATLAB software package is used to verify the correct operation of the communication system model.

\section{REVIEW OF THE LITERATURE}

In [1] the methods and algorithms of frame synchronization used in multi-antenna radio communication systems for orthogonal space-time block coding were considered. However, it did not evaluate the noise immunity of the signal when using QPSK modulation, which is not entirely consistent with the integrity of the information during the transmission session over the communication channel.

In the study [2] a method for solving the problem of identification of emergencies in the power supply system on the railway, using set theory, was proposed. However, the issue of transmitting diagnostic information to a remote operator was not addressed and the effect of destabilizing factors on the communication channel was not assessed. Such assessment is necessary to ensure the integrity of the information. In addition, due to remote monitoring of the system parameters, it is possible to identify an emergency or prevent its occurrence more quickly.

A complex mathematical model of a MIMO communication channel is proposed in [3]. The destabilizing factor is the additive Gaussian white noise there, which is common in the design of radio communication systems. This is because the additive Gaussian white noise refers to the fluctuation noise, which is represented as the sum of several independent oscillations. Fluctuation noise is a stationary ergodic random process with a Gaussian (normal) probability distribution, according to the central limit theorem. The spectral power density of the fluctuation noise always depends on the nature of the physical process of its formation. Most of the interferences that occur in practice belong to the group of additive interferences. This paper does not consider the effect of unintentional interference on the communication channel.

In [4] the noise immunity of existing radio lines with noise-like signals and digital types of modulation was investigated. To increase the noise immunity of communication systems, it was proposed in [4] to use nonstationary signal structures with variable center frequency and power spectral density. However, when assessing the potential noise immunity of radio lines, only the probability of a symbolic error in the radio channel is taken into account, which does not allow to take effective measures to adapt to the situation in the communication channel.

The study [5] developed a system of quantitative indicators of information security of the marine infrastructure. However, mathematical models of the communication system have not been developed and the impact of external influences on the communication channel has not been assessed, which indicates the lack of stability of the communication system used to external influences of intentional and unintentional interference.

In [6], the possibility of increasing LTE performance by using MIMO systems and frequency distribution methods is proposed. The authors [6] used OFDM technology. Analysis of the operation of OFDM technology 
showed that in the case of spectrum-concentrated interference, it is impossible to translate the carrier frequency signal into another range. As a result, some of the information transmitted over the communication channel will be lost because the frequency range through which the information is transmitted has been affected by external interference. As a result, the authors of [6] did not sufficiently substantiate the noise immunity to intentional and unintentional interference of the developed transmission channel using LTE technology.

The study [7] considered a system with changing parameters and used the difference-phase modulation of the second order, as well as the resistance of such a system to additive interference. As a result, it was possible to reduce the Doppler effect caused by the movement of the object and interference in the communication channel. Improving the quality of communication using the method proposed in [7] is due to the use of Phase-Difference Modulation. However, the effects of artificial interference were not taken into account, which certainly led to a deterioration in the quality of communication.

[8] considers the LC-RoF radio communication system, which allows transmitting mobile communication without hard transmissions during high-speed train movement. Hard transmissions occur when the range of radio transmitters is exceeded. As a result, the user may lose connection to the Internet or data. The developed system was tested on a Shinkansen high-speed train owned by the West Japan Railway Company. The LCRoF system can have two configurations: routing with wavelength division and routing based on an optical switch. When testing the LC-RoF radio system, only less efficient routing systems based on an optical switch were used. Scientists in [8] did not fully take into account the effect of external interference of artificial origin on the optical and radio data transmission.

In [9], a rather promising data transmission system was proposed, which combines VLC (Visible Light Communication) and PLC (Power Line Communication) technologies. As for disadvantages of the developed system in [9], it is shown that in the case of PLC, the transmission medium is shared between all subscribers, and the quality of the data transmission medium depends on the installation quality of the power supply system and is exposed to shortwave radio transmitters. The PLC signal transmission medium to the first transformer junction is running. It is shown that PLC modems will be affected by low-quality power consumers. When using the VLC system, subscribers must be in the line of sight, and the quality of data transmission depends on the operating conditions. It is known that the VLC system is negatively affected by solar radiation. The disadvantage is that the issue of intentional interference to the communication channel has not been fully addressed.

In [10], a high-frequency radio communication system with a millimeter band of $41 \mathrm{GHz}$ was proposed. To protect against the effects of atmospheric phenomena, the authors proposed to use narrowly directed antennas with a high gain. The disadvantages of this system include the fact that the transmitter and receiver of the radio signal must be in the line of sight, which complicates the application on rough terrain. However, when assessing the potential noise immunity of radio lines, the probability of a symbolic error in the radio channel is not investigated, which does not allow to take effective measures to adapt to the situation in the communication channel.

In [11], a chaotic scrambling algorithm was used to increase the stability of the communication system from artificial interference. Gaussian noise was added to the mathematical model to be studied to model the communication channel. As a disadvantage, it should be noted that the probability of bit error was not estimated. This disadvantage does not fully assess the resistance of the proposed algorithm to artificial interference.

Scientists in [12] solved the problems of design and analysis of control protocols for discrete-time multi-agent systems of the second order. Interference related to the time delay on equipment and communication channel has been simulated. The disadvantage of this study is that the effect of artificial interference on the communication channel has not been evaluated.

In [13] the problem of control of energy consumption and distribution of resources in the radio communication system was solved. As a disadvantage of this work, it should be noted that the quality of interference to the communication channel was taken into account only fluctuating interference. Other types of artificial interference were not considered.

In [14] the research of the system of mobile access points using millimeter waves for communication of highspeed trains, and the design of the extended system of mobile access points, including the specification of the physical layer and the single-frequency network, is presented. Experimental studies were conducted on the Seoul subway line. The simulation results showed that the extended system of mobile access points can provide broadband mobile wireless communication with a peak data rate exceeding 5 Gbps at a train speed of $500 \mathrm{~km} / \mathrm{h}$. However, when assessing the immunity of radio lines, the probability of a symbolic error in the radio channel is not investigated, which does not allow us to take effective measures to adapt to the situation in the communication channel.

A group of researchers in [15] considered the characteristics of the channel in the range of millimeter waves of the $5 \mathrm{G}$ communication standard for typical routes of highspeed rail communication system, including urban, rural, and tunnel, with straight and curved route shapes. Based on the obtained results, proposals were made to improve the symbol rate, subframe bandwidth, and polarization configuration for use in the design of a $5 \mathrm{G}$ communication system on typical routes of a high-speed railway communication system. However, when assessing the immunity of radio lines, the probability of a symbolic error in the radio channel is not investigated, which does not allow us to take effective measures to adapt to the situation in the communication channel. 
The efficiency of receivers and transmitters in noisy conditions depends on the choice of modulation methods, coding, and scheme of the receiver and transmitter. In works [1-15] this is not fully taken into account.

\section{MATERIALS AND METHODS}

Binary systems use two waveforms to transmit source binary symbols, each of which may contain one binary unit (or one bit) of information. However, with a larger alphabet of signals, each symbol sent can carry much more information. In particular, the alphabet containing $M$ characters ( $M$ different signals) allows you to transmit binary units of information for each sent character. $M$-th signals can be formed by multi-position manipulation of the oscillations of the carrier in the amplitude, frequency, phase.

The block diagram of a typical data transmission system is shown in Fig. 1. It is assumed that the message source generates statistically independent equally probable binary symbols with a rate of $R$ symbols per second, where $R$ is the performance of the source. This assumption is valid because the message of any source can be converted into a sequence of equally probable binary characters using the appropriate encoding method. Each symbol of the source in question carries one binary unit of information. Over the time interval, the $T_{M}$ source creates one of the $M=2^{R T_{M}}$ different equal-sequence sequences of binary symbols, each of which contains $R T_{M}$ binary units of information.

The encoder divides the sequence generated by the source into blocks with $k=R T_{M}$ symbols in each and sends a command to the modulator to generate one of the $M=2^{k}$ possible signals. In binary systems, $\mathrm{k}=1$ and the modulator selects only two possible signals with a duration of $T=T_{M}=1 / R$ each. When using coding with algebraic binary code, the encoder receives blocks with $\mathrm{k}>1$ source symbol. The encoder sends to the modulator a command to generate one of $M=2^{k}$ different sequences (codewords); any such sequence consists of $\mathrm{n}$ binary signals (where $n>k$ ) with duration $T=T M / n$ each. During the reception, the demodulation of individual binary signals with a duration of $T$, and not the whole sequence, the duration of which is equal to $T_{M}$. Then the demodulation results are fed to a logic circuit that converts $\mathrm{n}$ decisions made by the demodulator into $\mathrm{k}$ information symbols. In the $M$-th system, the encoder also receives blocks with $k>1$ binary source symbols and sends a command to the modulator to generate one of the $M=2^{k}$ different signals with a duration of $T_{M}$. However, in the receiver, the incoming signal is considered indivisible and is processed as a whole.

The modulator sends the selected signal to a communication channel in which this signal is distorted by additive white Gaussian noise. Depending on the context, the signal transmission speed will be understood as either the $M$-symbol transmission rate $\left(1 / T_{M}\right)$ or the source performance $(1 / T)$.

On the receiving side, in the case of a binary system without encoding information, a decision is made on the incoming signal as to which symbol was transmitted, and one of two possible values is issued. This eliminates the need for a decoder because the result of the decision (detection) is directly a binary digit that contains one binary unit of information. In a binary system with algebraic coding under the action of each binary signal, the demodulator (the first decision circuit) produces one of two possible values of its output value, and then the decoder converts each block of the output values of the demodulator into a sequence of $k$ binary symbols. In $M$-systems, the demodulator converts each $M$-signal into one of the $M$ possible values of its output value. In turn, the decoder for each of the $M$ possible values of the input signal produces a certain sequence of $k$ binary characters.

An objective comparison of so many different systems is quite a difficult task. If the frequency band of the system is insignificant (this assumption is often true when using $M$-signals or algebraic codes), it is more appropriate to compare systems at the same data rate.

The energy per binary unit (bit) of the source $E_{2}$ is related to the energy $E$ on the $M$-th symbol represented by the formula

$$
E_{2}=\left(\frac{1}{k}\right) E
$$

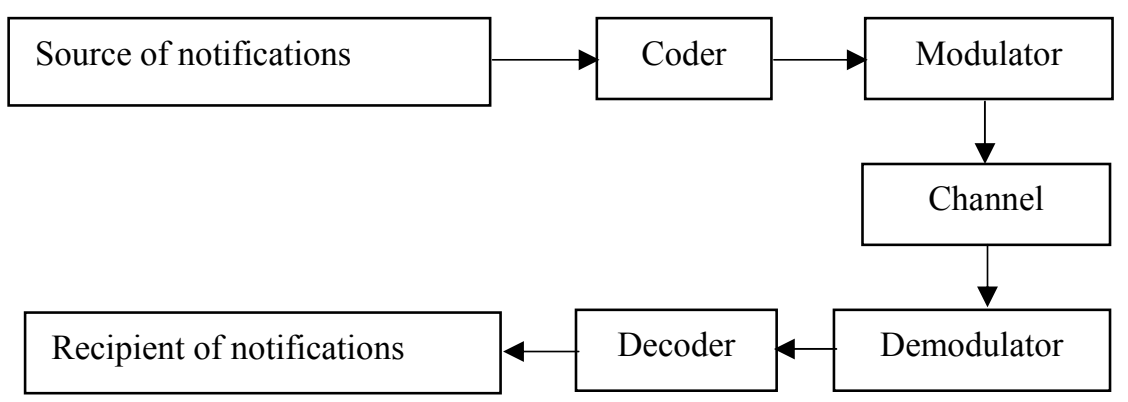

Figure 1 - Block diagram of the data transmission system 
where $k$ is the number of binary units of information in one character. The signal strength $S$, at a fixed performance of the source $R$, is determined by the formula:

$$
S=E^{2} R
$$

When comparing communication systems, it is proposed to use the probability of erroneous reception of the symbol, rather than the probability of erroneous reception of the binary unit, because between these two quantities there is no single universal deterministic relationship. Such specific relationships can be formulated for individual cases. Probably the most general assumption that will link the probability of erroneous reception of a character with the probability of erroneous reception of a binary unit is the following: if any $M$-th character is received incorrectly, the decoder randomly selects $k$ binary characters corresponding to each of the others $\left(2^{k-1}\right) M$ characters. Further, if there is a set of $M k$-bit binary sequences, then $M / 2$ of them contain in some arbitrary digit binary number 1 , and the rest $M / 2$-binary number 0 . Then from $2^{k-1}$ possible erroneous solutions, $2^{k-1}-1$ contain in this digit the same binary number as the transmitted sequence. The remaining $2^{k-1}$ sequences contain the opposite number in this digit. Under such assumptions, the average probability of erroneous reception of the binary unit (the probability of error in binary digit) $P_{e 2}$ is related to the probability of erroneous reception of the symbol $P_{e}$ by the ratio

$$
P_{e_{2}}=\left(\frac{2^{k-1}}{2^{k}-1}\right) P_{e}=\left(\frac{1}{2}\right) \frac{P_{e}}{\left(1-\frac{1}{2^{k}}\right)}
$$

In this case, relation (1) indicates the probability limit of erroneous reception of the symbol $P_{e}$ :

$$
P_{e_{2}} \leq \frac{P_{e}}{2\left(1-2^{-k}\right)}
$$

For large k, the limit defined by (2) practically coincides with

$$
P_{e_{2}} \leq 0.5 P_{e} .
$$

If the bandwidth of the system is limited, it is advisable to compare systems that occupy the same radio frequency band. Unfortunately, the spectrum width of the $M$ th or coded signal depends on the type of system. For signals with multi-position amplitude manipulation (multi-level signals), the width of the signal spectrum is essentially independent of $M$. However, at large $M$, this method of manipulation does not provide sufficient noise immunity during radio communication. When using frequency-manipulated or other orthogonal signals most commonly used in radio communications, the bandwidth of the system is proportional to $M$. At the same time, in all these systems, the data rate is proportional only to $\log _{2} M$. Assuming that the value of $M$ and the data rate are given, the graph of the probability of erroneous symbol reception from the signal-to-noise ratio can be considered as a curve taken at some fixed bandwidth of the system (in the whole range of signal-to-noise ratio).

It is shown that a more objective characteristic of the noise immunity of a discrete communication system than the probability of erroneous reception of the symbol Pe and the probability of erroneous reception of the binary unit $P_{e 2}$ is the equivalent probability of error $P_{e r r}$. It is defined as the probability of error in the binary channel when transmitting without redundant coding, in which the probability of error-free reception of a long segment of the message is the same as in this system. In particular, in the case of $M$-position redundant coding, it is possible to determine the equivalent probability of Rape error by the expression

$$
P_{\text {err }}=\frac{P_{e}}{\log _{2} M} .
$$

The problem of integrated design of communication systems, which usually consists of a compromise between the quality of the system, data rate, and bandwidth is a task with many unknowns and does not always allow to find a single universal basis for comparing communication systems. using $M$ or coded signals.

The transmission of information through the use of several phases of the same tone signal is a natural generalization of the method of binary phase manipulation.

Consider a four-phase system in which when using a binary signal BPM with phases, for example, $0^{\circ}-180^{\circ}$ can be transmitted completely independently, for coherent detection, on the same carrier another binary signal with phases $90^{\circ}-270^{\circ}$. One signal can be considered as a result of balanced modulation (multiplication by \pm 1 ) oscillations $\cos 2 \pi f_{0} t$, and the other as a result of balanced modulation of oscillations $\sin 2 \pi f_{0} t$. The input signal after filtering is fed to two coherent detectors. One of them uses the reference oscillation of the species $\cos 2 \pi f_{0} t$ (with compensation for phase shifts occurring in the transmission medium and the receiver filters) and emits the first signal and in-phase noise component. Another coherent detector uses a reference oscillation of the form $\sin 2 \pi f_{0} t$ and extracts the second signal and the quadrature component of the noise. It is shown that at any given moment of the hour, for example, at the moment of seeing a two-way virtual scheme, offending warehouses to the noise of an area. In such a rank, with the same smoothness of frequencies, it is possible to improve the speed of transmissions. According to the average value of the recipient, two units of the visa are assigned to $S T / n_{0}$, wherein in this case, $\mathrm{S}$ is the power of one of the two quadrature signals. Hence, to double the transmission speed with a constant probability of erroneous reception requires doubling the radiated power. It is established that there are no other values of the carrier phases that could be used to transmit another signal of binary BPM, free from cross-interference from the already considered two (C) Kvasnikov V. P., Yehorov S. V., Shkvarnytska T. Yu., Ornatskyi D. P., Kataieva M. A., 2021 DOI 10.15588/1607-3274-2021-4-2 
quadrature signals. This does not mean that other binary BPM signals can be transmitted on this carrier, for example, with phase values of $45^{\circ}-225^{\circ}$ i $135^{\circ}-315^{\circ}$. It is established that due to the presence of crosstalk, which reduces the signal resolution in the additive noise, the total radiation power should grow not in proportion to the number of binary signals combined, but much faster.

In the above case, the formation of binary signals BPM on each of the quadrature components of the carrier, the signal emitted at any time can be represented by the expression

$$
s(t)=a \cos 2 \pi f_{0} t+b \sin 2 \pi f_{0} t,
$$

where for each signal element $\mathrm{a}$ and $\mathrm{b}$ are independent and take the value +1 or -1 . It is known that the signal emitted at any time can be recorded as

$$
s(t)=\sqrt{2} \cos \left(\cos 2 \pi f_{0} t+\theta\right)
$$

where $\theta$ takes one of the values $45^{\circ}, 135^{\circ}, 225^{\circ}, 315^{\circ}$ Thus, the previously considered sum of two signals with phase values of $0^{\circ}$ or $180^{\circ}$ and $90^{\circ}$ or $270^{\circ}$ can be represented as a signal with one of the four possible phase values $\left(45^{\circ}, 135^{\circ}, 225^{\circ}, 315^{\circ}\right)$ carrying two binary units of information. Summarizing (3) in the case of $M$ phases, we obtain that each signal element of duration $T$ can be written as

$$
s(t)=\sqrt{S 2} \cos (\cos 2 \pi f t+\theta), \quad 0<t<T,
$$

where $\theta$ is one of the many equidistant values obtained, for example (Fig. 2) from the expression

$$
\theta_{m}=(2 \pi / M)(m-1), \quad m=1, \ldots, M
$$

An integer power of 2 is selected as $M: M=2^{k}$.

The power $S$ in (4) is the power of the full received signal.

We will be interested in measuring the value of the phase $\theta$. To do this, you can simply use a conventional phase detector with a reference voltage of the form $\theta$. Such a detector detects $\cos \theta_{m}$. This feature is ambiguous $\left[\cos \theta_{m}=\cos \left(2 \pi-\theta_{m}\right)\right]$ and only in the binary case when $\theta=0$ or $\pi$ ambiguity is eliminated. Phase determination $\theta$ is performed using two-phase detectors with a reference voltage of the form $\cos 2 \pi f_{0} t$ and $\sin 2 \pi f_{0} t$ a logic circuit that determines the ratio of certain components of the signal. One of the modulator options is a circuit that uses $M$ coherent or phase detectors with a reference voltage of the form $\cos \left(\cos 2 \pi f_{0} t+\theta_{m}\right)$ and selects the solution for the maximum (algebraic) output signal. This rule of the decision follows directly from the criterion of maximum plausibility.
In Fig. 2 shows a variant when $M=8$. Angle $\pi / \theta$ is the zone of correct reception if the phase value is transferred $\theta_{1}=0$. Assume that a signal with $\theta=0$ has been transmitted. Let us denote the in-phase and quadrature noise components at the input of the phase detector (connected after the bandpass filter) by $x(t)$ and $y(t)$, respectively. It's known that the input voltage detector is as follows

$$
v(t)=[\sqrt{2 s}+x(t)] \cos 2 \pi f_{0} t-y(t) \sin 2 f_{0} t,
$$

where $S$ is the signal strength, and $N=\bar{x}^{2}=\bar{y}^{2}$ - noise power, because the possible values of the signal phase differ from each other in magnitude $2 \pi / M$, then, as can be seen from Fig. 2, the reception will be correct if the phase of the voltage is determined (5) differs in absolute value from the phase of the transmitted signal by no more than $\pi / M$. The exact expression for the probability of erroneous character reception has the form

$P_{e}=1-\left(\frac{1}{2 \pi}\right) \int_{-\frac{\pi}{M}}^{\frac{\pi}{M}} e^{-\gamma}\left[1+\sqrt{4 \pi \gamma} \cos \theta e^{\gamma \cos ^{2} \theta}\left(\frac{1}{\sqrt{2 \pi}}\right)^{\sqrt{2 \gamma} \cos \theta} \int_{-\infty}^{-\frac{x^{2}}{2}} d x\right] d \theta$,

where the ratio of signal power/noise to interference power at the detector input is indicated by $\gamma=\frac{S}{N}$.

If a matched filter is used, then

$$
\gamma=S / N=E / n_{0},
$$

where $E$ is the energy of the signal element corresponding to the $M$-th symbol. The normalized signal-to-noise ratio is defined as the signal-to-noise ratio per binary unit of information:

$$
\gamma_{2}=\gamma / k=\gamma / \log _{2} M
$$

or for the case of an agreed filter

$$
\gamma_{2}=E_{2} / n_{0}=E / k n=E / n_{0} \log _{2} M .
$$

If we record the speed of information transmission, it is obvious that maintaining a constant probability of erroneous reception of the symbol with increasing $\mathrm{M}$ it is necessary to increase the normalized signal-to-noise ratio $\gamma_{2}$ in proportion to $M^{2} \log _{2} M$. The required frequency band decreases in proportion to . If we consider the frequency band to be fixed, then to keep the probability of erroneous reception of the symbol constant with increasing $M$, it is necessary to increase the normalized signal-to-noise ratio $\frac{\mathrm{M}}{\log _{2} M} \gamma_{2}$ also proportionally. While the speed of information transfer increases proportionally $\log _{2} M$. Note, however, that due to the increase in transmission rate, the signal power $S$ should increase in $\frac{\mathrm{M}}{\log _{2} M}$ proportion to $M^{2}$, and not. 


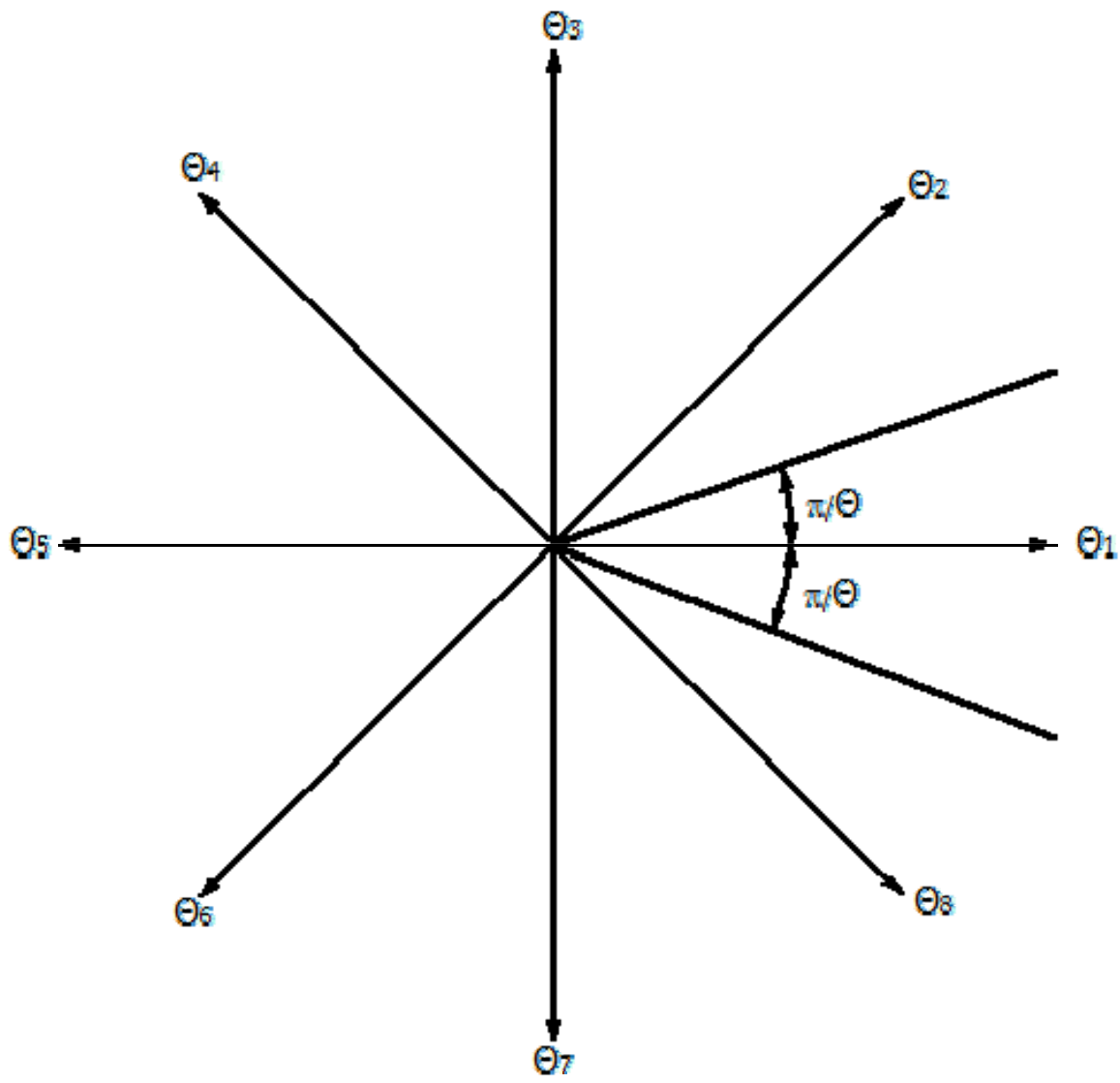

Figure 2 - The formation of the signal of the $M$-DFM (Fig. $M=8$ )

Assuming that when erroneously receiving any $M$-character, the decoder randomly selects $k$ binary characters corresponding to any of the remaining $2^{k}-1$ $M$-characters, then the probability of erroneous reception of the binary unit is associated with the probability of erroneous reception of the symbol relation (1) and, therefore, the above dependencies for the probability of erroneous reception of the symbol will also be valid for the probability of erroneous reception of the binary unit. However, in the case of multi-position FM, as follows from Fig. 2, the most probable errors are those in which the receiver instead of the phase of the transmitted signal is fixed to the adjacent phase value, and not some other. If we now choose a method of converting binary symbols to $M$, in which signals with adjacent phase values are represented by binary sequences that differ only in one digit (as, for example, in the Gray code), then each erroneous reception of the $M$-symbol will most likely mean error in only one digit of the binary sequence of $k$ digits. In the limit (which at very high signal/noise ratios)

$$
P_{e 2}=(1 / k) P_{e}=\left(1 / \log _{2} M\right) P_{e} .
$$

Equations (6) and (1) reflect the two extreme cases that characterize the relationship between the probability of erroneous reception of the binary unit and the probability of erroneous reception of the $M$-th symbol. In both cases, these probabilities are related by some algebraic coefficient, and the nature of the change in the probability of erroneous symbol reception as a function of signal energy in the presence of additive Gaussian noise is still largely determined by the exponential dependence on $\frac{\gamma}{M^{2}}$. Thus, with multi-position binary phase manipulation for any $M>4$, the required signal strength should increase approximately proportionally $M^{2}$.

\section{EXPERIMENTS}

A complete simulation of the communication system was performed to determine and verify the calculated parameters and model the interference in the communication channel. An example of such a model is shown in Fig. 3.

Description of the means of estimating the parameters of the communication system model, shown in Fig. 3:

1. The Error Rate Calculation block compares the input data from the transmitter with the output data of the receiver. The length of the filters must be taken into account in the block settings.

2. The Constellation Diagram allows you to observe the phase constellation.

3. The Spectrum Analyzer unit allows you to monitor the signal at the output of the communication channel.

4. The Find Delay block allows you to compare the received and transmitted signal, to find the probability of a bit error without knowing about the delay in the received signal. 


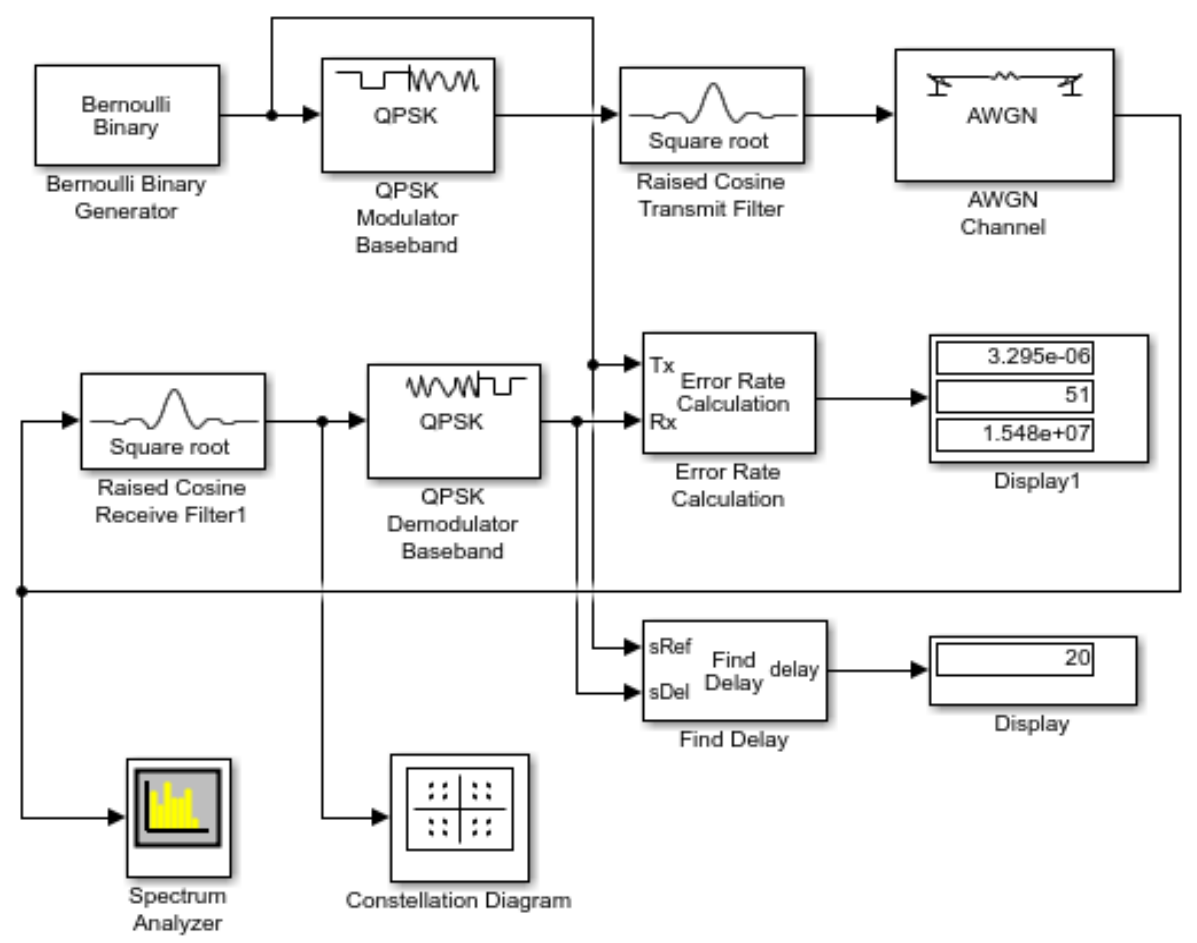

Figure 3 - Communication channel model, which was built in the SIMULINK software application from the MATLAB software package

Description of the blocks of the communication system model shown in Fig. 3:

1. In the configuration parameters of the model, select the discrete solver and the end time of the simulation.

2. The input to the communication channel model is provided by the Bernoulli Binary Generator block, which generates a random binary sequence of bits using the Bernoulli distribution.

3. Generated random binary sequence (Bernoulli generator), fed to the input of the modulator unit QPSK Modulator Baseband (Quadrature Phase Shift Keying, QPSK). At the receiving end, use the appropriate demodulator (QPSK Demodulator Baseband). In the modulator block settings, the "bit" parameter must be selected as the received data type, because the Bernoulli generator generates a sequence of bits. In the modulator block settings, select the "bit" parameter as the source data type.

4. A forming filter is installed at the output of the QPSK modulator and the input of the demodulator. The model developed in this study uses a Raised Cosine Transmit Filter. This type of shaping filter increases the sampling of the signal and filters the input signal using an FIR filter (finite impulse response) of the raised cosine with a square root, or a conventional FIR filter with a raised cosine.

5. The AWGN Channel is used as the transmission channel model. This unit adds white Gaussian noise to a real or complex input signal. In the block settings, set the parameter "Number of bits per character" to 2, as QPSK is used. Set the relative signal level to $1 / 8$, as the filter interpolation factor is 8 . The symbol period must correspond to the generator settings. The signalto-noise ratio is set to 10 .

\section{RESULTS}

To verify the correct operation of the communication channel model shown in Fig. 3, we will use the Bit Error Rate Analysis Tool of the MATLAB software package. The theoretical curve, which shows the signal-to-noise ratio, is shown in Fig. 4.

During the simulation of the communication channel at $\mathrm{Eb} / \mathrm{N} 0=10 \mathrm{~dB}$, the following results were obtained (Fig. 3).

- Bit error probability: $\mathrm{BER}=3.295 e-6$;

- The number of erroneous bits is 51 ;

- The total number of transmitted bits is $1.548 \mathrm{e}+7$.

\section{DISCUSSION}

Analyzing the simulation results obtained during the simulation of the communication channel, we can conclude that the model is built quite correctly. The fact that the model of the communication channel is correct is confirmed by the fact that the simulation results obtained during the simulation in Fig. 3 ( $\mathrm{BER}=3.295 e-6)$, coincide with the results obtained by the analysis tool Bit Error Rate Analysis Tool MATLAB software package, where $\mathrm{BER}=3.8 e-6 \quad$ (MATLAB software package, where $\mathrm{E}_{\mathrm{b}} / \mathrm{N}_{0}=10 \mathrm{~dB}$ ). For more accurate results, you need to increase the simulation time.

The disadvantage of QPSK is the complexity of the system. The advantage is a higher data rate. 


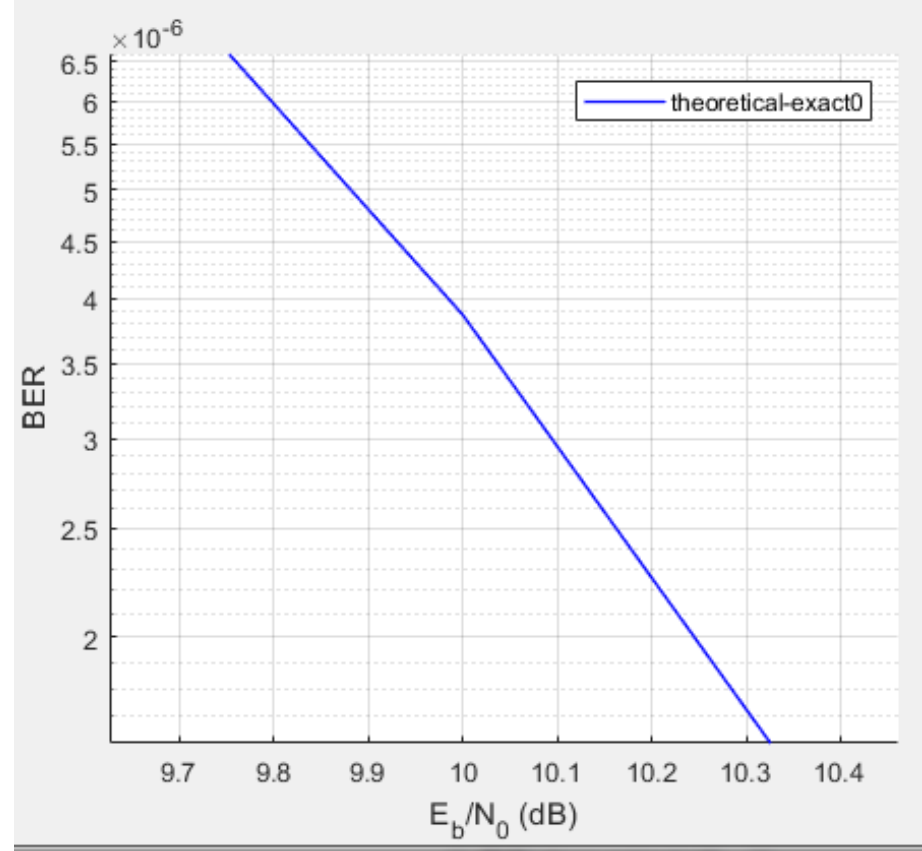

Figure 4 - Theoretical signal-to-noise ratio curve obtained using the Bit Error Rate Analysis Tool of the MATLAB software package. $\mathrm{E}_{\mathrm{b}} / \mathrm{N}_{0}$ - the ratio of the energy of the information bits per symbol to the spectral density of the noise power in decibels

\section{CONCLUSIONS}

The results of experimental studies of the communication channel fully confirmed the results of the mathematical model. As part of the study of the mathematical model, the verification of the correctness of the construction of the mathematical model (to ensure the correctness of signal filtering) is considered. The adequacy of the model is confirmed by the results of the experiment. The theoretical values of the Bit Error Rate (BER) obtained during the simulation of the communication channel are consistent with the results obtained using the Bit Error Rate Analysis Tool of the MATLAB software package.

The scientific novelty of the obtained results is that the proposed method of determining the parameters of information signals in the communication channel and increase the bandwidth of the communication channel during external interference to the signal transmission medium in the communication channel, which led to improved communication quality because QPSK technology was used.

The practical significance of the obtained results is that the method of mathematical modeling of information signal conversion processes during the process of formation, transmission, and selection of information signals is proposed.

Prospects for further research. The use of differential QPSK avoids the problem of lack of phase synchronization between transmitter and receiver. The use of QPSK with squaring offsets, $(\pi / 4-$ QPSK) allows mitigating the effects of changing the voltage of the signal of the carrier with a high slope when switching between characters.

\section{ACKNOWLEDGEMENTS}

The work was supported by the state budget research project of the National Aviation University "Methodology for building modern remote information and measurement systems" (state registration number 0117U002367), which was performed at the Department of Computerized Electrical Systems and Technologies.

\section{REFERENCES}

1. Tokar M. Development of blind frame synchronization for transfer system with differential space-time block coding, Technology audit and production reserves, 2020, Vol. 1, No. 2(51), pp. 30-34. DOI: https://doi.org/10.15587/23128372.2020.196277

2. Holub H., Kulbovskyi I., Skliarenko I., Bambura O., Tkachuk M. Research of methods for identification of emergency modes of power supply system in transport infrastructure projects, Technology audit and production reserves, 2019, Vol. 4, No. 5(49), pp. 34-36. DOI: 10.15587/2312-8372.2019.182830

3. Kalantaievska S., Kuvshynov O., Shyshatskyi A., Salnikova O., Punda Y., Zhuk P., Zhuk O., Drobakha H. L. Development of a complex mathematical model of the state of a channel of multiantenna radio communication systems, Eastern-European Journal of Enterprise Technologies, 2019, Vol. 3, No. 9(99), pp. 2130. DOI: 10.15587/1729-4061.2019.166994

4. Korchinskyi V., Hadzhyiev M., Pozdniakov P., Kildishev V., Hordiichuk V. Development of the procedure for forming non-stationary signal structures based on multicomponent LFM signals, Eastern-European Journal of Enterprise Technologies, 2018, Vol. 6, No. 9(96), pp. 29-37. DOI: 10.15587/17294061.2018.151816

5. Blintsov O., Maidaniuk P. Development of informationallyprotected system of marine water area monitoring, EasternEuropean Journal of Enterprise Technologies, 2017, Vol. 6, No. 9(90), pp. 10-16. DOI: 10.15587/1729-4061.2017.118851

6. Loshakov V. A., Al-Janabi Hussam Dheaa, Hussein Yahya Tareq, Nooh Taha Nasif Adaptive modulation in LTE technology by using ofdma and SC-FDMA with MIMO, Eastern- 
European Journal of Enterprise Technologies, 2013, Vol. 2, No. 9(62), pp. 8-11.

7. Dolinskiy R. Analysis of system with variable parameters, invariant to additive interference, Eastern-European Journal of Enterprise Technologies, 2015, Vol. 4, No. 4(74), pp. 10-16. DOI: $10.15587 / 1729-4061.2015 .47729$

8. Atsushi Kanno, Pham Tien Dat, Naokatsu Yamamoto, Tetsuya Kawanishi, Nagateru Iwasawa, Nariya Iwaki, Kazuki Nakamura, Kunihiro Kawasaki, Naoki Kanada, Naruto Yonemoto, Yosuke Sato, Masato Fujii, Katsuya Yanatori, Nobuhiko Shibagaki, Kenichi Kashima High-Speed Railway Communication System Using Linear-Cell-Based Radio-Over-Fiber Network and Its Field Trial in 90-GHz Bands, Journal of lightwave technology, 2020, Vol. 38, No. 1, pp. 112-122. DOI: $10.1109 /$ JLT.2019.2946691

9. Sobia Baig, Hafiz Muhammad Asif, Tariq Umer, Shahid Mumtaz, Muhammad Shafiq, Jin-Ghoo Choi High Data Rate Discrete Wavelet Transform-Based PLC-VLC Design for 5G Communication Systems, IEEE Access, 2020, Vol. 6, pp. 52490-52499. DOI: 0.1109/ACCESS.2018.2870138

10. Guangrong Yue, Daizhong Yu, Long Cheng, Qifu Lv, Zhigang Luo, Qing Li, Junxin Luo, Xu He Millimeter-Wave System for High-Speed Train Communications Between Train and Trackside: System Design and Channel Measurements, IEEE transactions on vehicular technology, 2019, Vol. 68, No. 12, pp. 11746-1761. DOI: 101109/TVT.2019.2919625
11. Yongqing Fu, Shengnan Guo, Zhixin Yu The Modulation Technology of Chaotic Multi-Tone and its Application in Covert Communication System, IEEE Access, 2019, Vol. 7, pp. 122289-122301. DOI: 10.1109/ACCESS.2019.2937895

12. Lyulong He, Jiaqiang Zhang, Yueqi Hou, Xiaolong Liang, Peng Bai Time-Varying Formation Control for Second-Order Discrete-Time Multi-Agent Systems With Directed Topology and Communication Delay, IEEE Access, 2019, Vol. 7, pp. 33517 3352. DOI: 10.1109/ACCESS.2019.2904663

13. Zuolin Dong, Jiahong Wei, Xiaoyu Chen, Pengfei Zheng Energy Efficiency Optimization and Resource Allocation of CrossLayer Broadband Wireless Communication System, IEEE Access, 2020, Vol. 8, pp. 50740-50754. DOI: 10.1109/ACCESS.2020.2978034

14. Junhyeong Kim, Mathis Schmieder, Michael Peter, Heesang Chung, Sung-Woo Choi, Ilgyu Ki, Youngnam Han A comprehensive study on mmWave-based mobile hotspot network system for high-speed train communications, IEEE Transactions on Vehicular Technology, 2018, vol. 68, No. 3 pp. 2087-2101. DOI: 10.1109/TVT.2018.2865700

15. Danping He, Ai Bo, Guan Ke, Zhong Zhangdui, Hui Bing, Kim Junhyeong, Chung Heesang, Kim Ilgyu Channel measurement, simulation, and analysis for highspeed railway communications in 5G millimeter-wave band, IEEE Trans. Intell. Transp. Syst., 2018, Vol. 19, No. 10, pp. 3144-3158. DOI: 10.1109/TITS.2017.2771559

\section{УДК 004.94}

\section{МОДЕЛЮВАННЯ СИСТЕМИ ЗВ’ЯЗКУ 3 МЕТОЮ ДОСЛІДЖЕННЯ ДІЇ ЗАВАД В СЕРЕДОВИЩІ ПЕРЕДАЧІ}

Квасніков В. П. - професор, доктор технічних наук, завідувач кафедри комп'ютеризованих електротехнічних систем та технологій Національного авіаційного університету, Київ, Україна.

Сгоров С. В. - кандидат технічних наук, доцент кафедри комп'ютеризованих електротехнічних систем та технологій Національного авіаційного університету, Київ, Україна.

Шкварницька Т. Ю. - доцент, кандидат технічних наук, доцент кафедри комп'ютеризованих електротехнічних систем та технологій Національного авіаційного університету, Київ, Україна.

Орнатський Д. П. - доктор технічних наук, професор кафедри комп'ютеризованих електротехнічних систем та технологій Національного авіаційного університету, Київ, Україна.

Катаєва М. О. - кандидат технічних наук, доцент кафедри доцент кафедри комп’ютеризованих електротехнічних систем та технологій Національного авіаційного університету, Київ, Україна.

\section{АНОТАЦІЯ}

Актуальність. Розглянуто задачу створення моделі передачі та перетворення інформації, розглянуті процеси перетворення інформації в передавачах та приймачах, розглянутий процес дії дестабілізуючих факторів на канал зв'язку Об'єктом дослідження $\epsilon$ процес формування, передачі, та відновлення радіосигналів.

Метод. Запропоновано математичну модель, яка дозволяє оцінити стійкість сигналу в каналі зв'язку ще на етапі проектування телекомунікаційних систем різного призначення з урахуванням дії завад в середовищі передачі інформаційного сигналу. Проведено оцінку дії завади на канал зв'язку завдяки використанню співвідношення сигнал/шум. Запропоновано метод визначення параметрів інформаційних сигналів у каналі зв'язку та підвищення пропускної здатності під час дії зовнішніх завад на середовище передачі сигналу в каналі зв'язку.

Результати. Була отримана математична модель каналу зв'язку, яка враховує зовнішні дестабілізуючі фактори, які можуть діяти на канал та апаратуру зв'язку. Розроблена модель містить метод верифікації, який дозволяє визначити ії коректність.

Висновки. Вдосконалено метод передачі інформації шляхом додавання методу верифікації. Значення бітової помилки, що було отримано під час моделювання каналу зв'язку співпадає зі значенням бітової помилки під час процесу верифікації, що свідчить про правильність розглянутої математичної моделі каналу зв'язку. Тому цей метод моделювання каналу зв'язку може бути рекомендованим для використання під час проектування та дослідження телекомунікаційних систем.

КЛЮЧОВІ СЛОВА: канал зв’язку, модуляція, якість зв'язку, відновлення сигналу, демодуляція, фільтрація.

УДК 004.94

\section{МОДЕЛИРОВАНИЕ СИСТЕМЫ СВЯЗИ С ЦЕЛЬЮ ИССЛЕДОВАНИЯ ДЕЙСТВИЯ ПОМЕХ В СРЕДЕ ПЕРЕДАЧИ}

Квасников В. П. - профессор, доктор технических наук, заведующий кафедры компьютеризированных электротехнических систем и технологий Национального авиационного университета, Киев, Украина.

Егоров С. В. - кандидат технических наук, доцент кафедры компьютеризированных электротехнических систем и технологий Национального авиационного университета, Киев, Украина.

(C) Kvasnikov V. P., Yehorov S. V., Shkvarnytska T. Yu., Ornatskyi D. P., Kataieva M. A., 2021

DOI 10.15588/1607-3274-2021-4-2 
Шкварницкая Т. Ю. - доцент, кандидат технических наук, доцент кафедры компьютеризированных электротехнических систем и технологий Национального авиационного университета, Киев, Украина.

Орнатський Д. П. - доктор технических наук, профессор компьютеризированных электротехнических систем и технологий Национального авиационного университета, Киев, Украина.

Катаева М. А. - кандидат технических наук, доцент кафедры компьютеризированных электротехнических систем и технологий Национального авиационного университета, Киев, Украина.

\section{АННОТАЦИЯ}

Актуальность. Рассмотрена задача создания модели передачи и преобразования информации, процессы преобразования информации в передатчиках и приемниках, процесс действия дестабилизирующих факторов на канал связи объект исследования процесс формирования, передачи и восстановления радиосигналов.

Метод. Предложена математическая модель, позволяющая оценить устойчивость сигнала в канале связи на этапе проектирования телекоммуникационных систем различного назначения с учетом влияния помех в среде передачи информационного сигнала. Влияние помех на канал связи оценивается за счет использования соотношения сигнал/шум. Предложен метод определения параметров информационных сигналов в канале связи и повышения пропускной способности при действии внешних помех на среду передачи сигнала в канале связи.

Результаты. Получена математическая модель канала связи, учитывающая внешние дестабилизирующие факторы, которые могут действовать на канал и аппаратуру связи. Разработанная модель содержит метод верификации, позволяющий определить ее правильность.

Выводы. Улучшен способ передачи информации путем добавления метода верификации. Величина битовой ошибки, полученной при моделировании канала связи, совпадает с величиной битовой ошибки в процессе верификации, что свидетельствует о правильности математической модели рассматриваемого канала связи. Поэтому данный метод моделирования канала связи может быть рекомендован для использования при проектировании и исследовании телекоммуникационных систем.

КЛЮЧЕВЫЕ СЛОВА: канал связи, модуляция, качество связи, восстановление сигнала, демодуляция, фильтрация.

\section{ЛІТЕРАТУРА / ЛИТЕРАТУРА}

1. Tokar M. Development of blind frame synchronization for transfer system with differential space-time block coding / $\mathrm{M}$ Tokar // Technology audit and production reserves. - 2020. Vol. 1, No. 2(51) - P. 30-34. DOI https://doi.org/10.15587/2312-8372.2020.196277

2. Holub H. Research of methods for identification of emergency modes of power supply system in transport infrastructure projects / [H. Holub, I. Kulbovskyi, I. Skliarenko et al.] // Technology audit and production reserves. -2019 . - Vol. 4, No. 5(49) P. 34-36. DOI: $10.15587 / 2312-8372.2019 .182830$

3. Kalantaievska S. Development of a complex mathematical model of the state of a channel of multi-antenna radio communication systems / [S. Kalantaievska, O. Kuvshynov, A. Shyshatskyi et al.] // Eastern-European Journal of Enterprise Technologies. - 2019. - Vol. 3, No. 9(99) - P. 21-30. DOI: 10.15587/1729-4061.2019.166994

4. Korchinskyi V. Development of the procedure for forming non-stationary signal structures based on multicomponent LFM signals / [V. Korchinskyi, M. Hadzhyiev, P. Pozdniakov et al.] // Eastern-European Journal of Enterprise Technologies. 2018. - Vol. 6, No. 9(96) - P. 29-37. DOI: 10.15587/17294061.2018.151816

5. Blintsov O. Development of informationally-protected system of marine water area monitoring / O. Blintsov, P. Maidaniuk // Eastern-European Journal of Enterprise Technologies. - 2017. Vol. 6, No. 9(90) - P. 10-16. DOI: 10.15587/1729 4061.2017.118851

6. Loshakov V. A. Adaptive modulation in LTE technology by using ofdma and SC-FDMA with MIMO / [V. A. Loshakov, AlJanabi Hussam Dheaa, Hussein Yahya Tareq, Nooh Taha Nasif] // Eastern-European Journal of Enterprise Technologies. 2013. - Vol. 2, No. 9(62) - P.8-11.

7. Dolinskiy R. Analysis of system with variable parameters, invariant to additive interference / R. Dolinskiy // EasternEuropean Journal of Enterprise Technologies. - 2015. - Vol. 4, No. 4 (74) - P. 10-16. DOI: 10.15587/1729-4061.2015.47729

8. Atsushi Kanno. High-Speed Railway Communication System Using Linear-Cell-Based Radio-Over-Fiber Network and Its Field Trial in 90-GHz Bands / Atsushi Kanno, Pham Tien Dat, Naokatsu Yamamoto, Tetsuya Kawanishi, Nagateru Iwasawa, Nariya Iwaki, Kazuki Nakamura, Kunihiro Kawasaki, Naoki
Kanada, Naruto Yonemoto, Yosuke Sato, Masato Fujii, Katsuya Yanatori, Nobuhiko Shibagaki, Kenichi Kashima // Journal of lightwave technology. - 2020. - Vol. 38, No. 1 - P. 112-122. DOI: 10.1109 / JLT.2019.2946691

9. Sobia Baig. High Data Rate Discrete Wavelet Transform-Based PLC-VLC Design for 5G Communication Systems / [Sobia Baig, Hafiz Muhammad Asif, Tariq Umer et al.] // IEEE Access. - 2020. - Vol. 6. -P. 52490-52499. DOI: 0.1109/ACCESS.2018.2870138

10. Guangrong Yue. Millimeter-Wave System for High-Speed Train Communications Between Train and Trackside: System Design and Channel Measurements / [Guangrong Yue, Daizhong $\mathrm{Yu}$, Long Cheng et al.] // IEEE transactions on vehicular technology. - 2019. - Vol. 68, No. 12 - P. 11746-1761. DOI: 101109/TVT.2019.2919625

11. Yongqing Fu. The Modulation Technology of Chaotic MultiTone and its Application in Covert Communication System / Yongqing Fu, Shengnan Guo, Zhixin Yu // IEEE Access. 2019. - Vol. 7 - P. 122289-122301. DOI: 10.1109/ACCESS.2019.2937895

12. Lyulong He. Time-Varying Formation Control for SecondOrder Discrete-Time Multi-Agent Systems With Directed Topology and Communication Delay / [Lyulong He, Jiaqiang Zhang, Yueqi Hou et al.] // IEEE Access. - 2019. - Vol. 7 P. 33517-3352. DOI: 10.1109/ACCESS.2019.2904663

13. Energy Efficiency Optimization and Resource Allocation of Cross-Layer Broadband Wireless Communication System / [Zuolin Dong, Jiahong Wei, Xiaoyu Chen, Pengfei Zheng] // IEEE Access. - 2020. - Vol. 8 - P. 50740-50754. DOI: 10.1109/ACCESS.2020.2978034

14. Junhyeong Kim. A comprehensive study on mmWave-based mobile hotspot network system for high-speed train communications / [Junhyeong Kim, Mathis Schmieder, Michael Peter, Heesang Chung et al.] // IEEE Transactions on Vehicular Technology. - 2018. - Vol. 68, No. 3 - P. 2087-2101. DOI: 10.1109/TVT.2018.2865700

15. Danping He Channel measurement, simulation, and analysis for highspeed railway communications in $5 \mathrm{G}$ millimeter-wave band / [Danping He, Bo Ai, Ke Guan et al.] // IEEE Trans. Intell. Transp. Syst. - 2018. - Vol. 19, No. 10 - P. 3144-3158. DOI: 10.1109/TITS.2017.2771559. 